\title{
Mis/Representations of Asian/Americans in the Curricula: Perspectives from Second-Generation Japanese American Youth
}

\author{
Rachel Endo \\ Hamline University \\ U. S.A.
}

ABSTRACT: This case study explores how six second-generation Japanese American youth recalled learning about cultural diversity at their high schools, particularly information that was intended to represent their identities as ethnic and racial minorities. Semi-structured interviews were used to investigate how the participants made sense of curricular content that did not represent their experiences accurately or completely. Site documents including course documents and syllabi were also analyzed. The findings suggest that (a) Asian/Americans have largely been excluded from definitions of diversity and multiculturalism and (b) when White teachers included lessons intended to teach about Asian/Americans, the content generally reinforced Orientalist stereotypes, particularly colonizing images of the cultural exoticism-pathology binary and/or racial sameness. The implications section details practical strategies for K-12 teachers to include more balanced information about Asian/American experiences in the curricula.

\author{
Explanations of Terms \\ Literature Review \\ Method \\ Multiculturalism without Asian Americans? \\ Images of Cultural Pathology and Other Orientalist Stereotypes \\ Implications for Practice \\ References
}

Style's (1996) classic analogy that school curricula should represent both mirrors and windows for all learners reinforces a strong rationale for why K-12 educators must be mindful about how they teach about human diversity. According to this paradigm, learners must not only see themselves represented in the curricula (mirrors), but should also see others represented (windows) in order to develop a balanced understanding of other and self. Imbalance in either way could pose socio-emotional challenges for young people that could manifest into attitudes of ethnocentrism (if curricula are mostly mirrors) or internalized selfhatred (if curricula are primarily windows). Leading scholars of critical multiculturalism such as Banks (2009) and Grant and Sleeter (2006) have pointed out that while multicultural education has been shown to benefit all students, the curricular content at the majority of U.S. K-12 schools (a) still mirrors Eurocentric perspectives and thus provides mostly windows for students 
of color, and (b) may create mirrors for "non-White" learners, but in ways that often result in well-meaning White teachers teaching about culture, difference, and identity in essentializing and stereotypical ways. Even at the most basic levels of multicultural integration, scholars of Asian American education have found that Asian Americans are generally represented in the curricula as exotic foreigners, model minorities, and nameless citizens, or that the foci narrowly target only specific ethnic groups or historical events (e.g., Lee, 2005; Pang, 2006).

This case study, which is part of a larger multi-site research project focusing on the experiences of Japanese Americans from immigrant families, investigates the ways in which six second-generation Japanese American youth interpreted how they learned about cultural diversity at their high schools, particularly themes that their White teachers thought pertained to their identities as ethnic and racial minorities. The purpose is to tackle the complex question of how the participants, as Asian American students, have made sense of and responded to curricula that their schools claimed were multicultural but inherently fell short of expectations. In addition to determining whether the curricula were mirrors or windows for the participants, an ancillary goal was to analyze how their ethnic and racial identities were represented in site documents including assignment handouts, course catalogs, and course syllabi. Critical curriculum theories (e.g., Apple, 1990; Banks, 2006, 2009; Goodwin, 2011; Kaomea, 2000; Style, 1996) were used as lenses to identify the mismatch between the actual diversity of Asian/American experiences and how Asian/Americans were represented in classroom discussions and multicultural curricula. This study thus seeks to contribute to larger debates about the educational implications of curricular efforts that intend to promote cultural awareness but instead end up generating inaccurate and incomplete assumptions about identity and the purpose of multicultural education.

\section{Explanation of Terms}

Following the advice of Espiritu (1993), the participants are identified as both Asian American (pan-ethnic identities) and Japanese American (specific ethnic identity) to emphasize that they are American citizens and not foreigners. To clarify, the intent is not to encourage labeling that categorizes all Asian Americans as the same, but rather to spotlight the reality that Asian Americans across ethnic groups share the common experience of being racialized and stereotyped by outsiders (Kibria, 2002). The participants do have distinct identities because they are the children of new-wave Japanese immigrants. That is, because most existing educational research on Japanese Americans focuses on the descendants of the earliest waves of Japanese immigrants (Adler, 1998; Pak, 2002), the participants in my study have qualitatively different experiences compared to second-generation Japanese Americans who grew up in the 1910s1940s or their same-age Japanese American peers who are among the fourth- 
and-subsequent generations (Endo, 2007). At the same time, because the participants attended public schools in the Midwest where Asian American students are a numeric minority, race became a salient issue that defined their experiences.

Moreover, the terms Asian/American and Japanese/American (PalumboLin, 1999) are used to reference instances when the symbolic boundaries between Asia/Japan and America were ambiguous, conflated, or incomplete. In all, it must be recognized that the politics of naming is both a complicated and contentious process. For instance, while the participants were born in the United States, they did not identify themselves as just "American" because they have probably internalized the dominant mindset that only Whites are authentic Americans (Tuan, 1998; Wu, 2002). At school, the participants reported that their White peers and teachers primarily viewed them as Asian, usually in racially stereotypical ways that did not consider the nuances of their identities. Thus, I use multiple labels in this text to de-center the notion that being "American" is only reserved for members of the dominant culture, while acknowledging that Asian American youth do experience significant racialization during their K-12 years (Marinari, 2006).

\section{Literature Review}

Style's (1996) mirror-window analogy requires further explication and scholarly critique, as the goal of multicultural education is not (and should not be) simply to include more information about ethnic and racial minorities. At the most basic level, however, Banks (2006) reminds us that given that multicultural education seeks to raise cultural awareness and simultaneously promote prejudice reduction, teachers must especially take care to evaluate the content they plan to teach for bias and stereotypes. However, compared to other populations of color, Asian American experiences are more often excluded in multicultural initiatives or have not been taught from critical academic perspectives; scholars have attributed this to the persistence of racial stereotypes that disproportionately depict them as either invisible minorities or model minorities (Lee, 1996). To remedy the mirrors-windows gap, as well as to promote the teaching of critical multiculturalism, scholars of multicultural education have called for large-scale curricular reform that challenges teachers to reconsider how they conceptualize and teach about diversity. Banks (2009, p. 19) identifies a model of multicultural integration that differentiates among the various types of multiculturalism:

1. Level 1/Contributions Approach: a cursory approach to teaching diversity such as presenting information about ethnic heroes and holidays. The format usually includes one-time events such as diversity days or heritage months. 
2. Level 2/Additive Approach: adding multicultural content and themes such as a course or unit on ethnic literature. However, the curricula still privilege monocultural perspectives.

3. Level 3/Transformative Approach: multiple perspectives are consistently integrated into the official curricula without privileging any dominant viewpoint.

4. Level 4/Social Actions Approach: students learn how to make decisions and take action to solve real-world social problems. The approach includes all elements of Level 3.

In addition to analyzing how multicultural content could be integrated into the curricula as described above, there is also a need to situate curricular imbalances within the proper historical and social contexts to ascertain how the politics of representation most certainly shapes the scope of knowledge that is de/valued in the schools (Apple, 1990). While the exclusion and misrepresentations of Asian/Americans in the K-12 curricula cannot be easily traced to a single group or institution, it will be helpful to briefly discuss how racialized stereotypes of Asian-origin people have shaped the content of multicultural initiatives that tend to frame diversity in limiting terms. In his definition of Orientalism, Said (1978) provocatively contended, "The Orient was almost a European invention, and has been since antiquity as a place of romance, exotic beings, haunting memories and landscapes, remarkable experiences" (p. 1). Thus, Orientalism, similar to the discourse of tribalism that exotifies and pathologizes indigenous populations (Lutz \& Collins, 1993), has been used as a theoretical paradigm to define Asian/American people in colonizing and "Othering" ways.

Orientalist images have undoubtedly shaped two prominent images of Asian/Americans: model minorities and perpetual foreigners ( $\mathrm{Ng}$, Lee, \& Pak, 2007). The model-minority image, which depicts Asian/Americans as an exceptionally successful population, has been widely critiqued as a damaging stereotype (Osajima, 1988; Wing, 2007). Japanese Americans have especially been constructed as model minorities because of the belief that even after being illegally incarcerated during World War II, they have supposedly assimilated into (White) American society while refusing to complain about White racism (Glenn, 1988; Endo, 2007). Glenn (1988) further theorizes that the majority of Japanese American children who were raised from the 1950s onward underwent rapid cultural assimilation because their families felt extreme societal pressure to maintain the model-minority image. That is, the Japanese American community supposedly desired to rehabilitate the "bad-Oriental image" that had led to their incarceration in the first place following the Pearl Harbor incident. However, Asian Americans, even groups like Japanese Americans who have had a long presence in the United States, are burdened by what Takaki (1989) noted as the reality that "stereotypes and myths of Asians as aliens and foreigners are pervasive in American society" (p. 6). 
While scholars of multicultural education have identified structural gaps in curricular documents and instructional practices that marginalize Asian American students, there is a shortage of research that analyzes how Asian American K-12 youth relate to (and respond to) the actual multicultural curricula taught at their schools. There are even fewer studies that specifically focus on Japanese American students in contemporary contexts. Amos (2008), Kondo (1998), Morimoto (1997), and Yamaguchi (2005) are examples of the few known scholars who have introduced the academic community to the educational experiences of immigrant and second-generation Japanese American youth, mostly around issues of ethnic-identity formation, heritage-language maintenance, and negotiating life between home and school. Thus, this study, tackles how second-generation Japanese American youth, as Asian American students, have made sense of and responded to curricula that their schools claimed were supposed to promote diverse perspectives but inherently ended up mostly perpetuating racialized and racist stereotypes of Asian/Americans.

\section{Method}

This study took place in 2008. The setting is a midsize urban city in the Midwest that is over 90 percent White. People of Asian ancestry account for approximately 2 percent of the area's population. The largest Asian ethnic groups are Chinese, Indian, and Vietnamese while Japanese are the smallest. The participants attended two public school districts with the following demographics; however, the specific characteristics of individual schools were excluded to maintain confidentiality:

1. Large Urban District (LUD) is the largest public district in the state. It serves approximately 60 percent students of color and 40 percent White students. African Americans account for roughly 30 percent of the student population, Latinas/Latinos 25 percent, and Asian Americans 2 percent.

2. Midsize Suburban District (MSD) is known for enrolling large numbers of students from affluent backgrounds. MSD serves approximately 94 percent White students and 6 percent students of color. As the largest "non-White" group, Latina/Latino students represent approximately 2 percent of the total student population; Asian American students account for just under 2 percent; and African Americans at 1.5 percent. In both school districts, Asian Americans are a numeric minority, representing less than 2 percent of the total student body.

As of the 2007-2008 school year, over 95 percent of all K-12 teachers in both districts were White, which parallels national trends in the United States, and further shows a mismatch between the diversity of the student body and the predominantly White composition of the teaching force (Cross, 2004). 
Significantly, all participants had had only White teachers throughout their entire K-12 schooling experiences. Participants who attended LUD schools reported seeing a few teachers of color, but none were Asian American.

Six Japanese American youth participated in this study. Identifying information including the real names of participants, schools/school districts, teachers, and the larger community are excluded to maintain confidentiality assurances. Pseudonyms are used in place of real names.

Table 1. List of Participants

\begin{tabular}{|c|c|c|c|}
\hline Participant's Name & Gender & Grade Level & School District \\
\hline Danny & Male & Twelfth & MSD \\
\hline Haruka & Female & Eleventh & LUD \\
\hline Mariko & Female & Twelfth & MSD \\
\hline Naomi & Female & Tenth & MSD \\
\hline Ryan & Male & Eleventh & LUD \\
\hline Shinichi & Male & Eleventh & LUD \\
\hline
\end{tabular}

Institutional Review Board permission to conduct research with minors was obtained before data collection began. After approval was secured, participants were recruited through my personal and professional networks as a community educator. Specifically, I asked Japanese immigrant women whom I met through our common work with an organization focusing on diversity education to help identify prospective participants. I then contacted the youth by e-mail or phone, or approached them in person in public settings. The interviews took place in a variety of places including coffee shops, homes, and restaurants. Semi-structured interviews were used with each lasting approximately 60 to 120 minutes; all were in English. While a total of 20 youth were interviewed, six were selected for this article to represent both genders equally. Also of interest was whether school type (large urban versus midsize suburban) made any significant differences in how the youth learned about cultural diversity at school.

Concurring with Clandinin and Connelly (2000), as well as Josselson (2006), all attempts were made to honor each participant's personal narratives while concomitantly situating how each person's individual perspectives informed collective experiences that are uniquely tied to issues of identity formation in specific social contexts. As Josselson (2006) states: "Rooted in interpretive hermeneutics and phenomenology, [narrative inquiry] strives to preserve the complexity of what it means to be human and to locate its observations of people and phenomenon in society, history, and time" (p. 3). In this spirit, the research critiques the conventional Eurocentric understanding that a narrative is simply one person's subjective "story to tell." Instead, the goal here is to illustrate how individual narratives inform group-specific experiences, particularly around topics of belonging and identity. Finally, in addition to synthesizing themes that 
emerged from the interviews, site documents such as assignment handouts, course catalogs, and syllabi were analyzed for reemerging assumptions, definitions, and terms related to Asian/American experiences, using Kaomea's (2000) problems-based interpretive method, which involves closely explicating curricular language for connotative biases.

To clarify, I only included the narratives of the youth-participants. Interviews with parents, peers, and teachers were not included in the results section, thus prohibiting the inclusion of a full range of perspectives. However, since few studies directly solicit firsthand input from youth themselves, the indepth interviews will serve as significant sources of primary evidence. Finally, because I identify as a second-generation Japanese American, I was able to establish rapport with participants based on our shared ethnic/racial and generational identities. However, I do not claim to authentically represent all second-generation Japanese Americans or to "speak for" them as an expert. Rather, I viewed myself as an advocate who also wanted to learn from them about how what they have learned at school has impacted their identities as young Asian Americans.

\section{Multiculturalism without Asian Americans?}

All participants reported that beyond one-time courses or events that did not require school-wide participation, Asian Americans were mostly absent from the curricula. Some participants mentioned that their schools offered a couple of elective course in ethnic studies. However, as electives that did not require the participation of all students, the courses had little wide-scale impact on raising cultural awareness, and further, did not appear to equally cover all Americans of color. For instance, Ryan's high school, which is one of the most racially diverse in the area, has offered African American and Mexican American history courses since the early 2000s. Ryan mentioned that most students who took these courses were either students of color who were interested in learning about their heritages or White students who were looking for an "easy course" to fulfill their graduation requirements.

Similarly, Mariko's school had regularly offered an elective course on ethnic studies. A White teacher who identified herself as an expert on diversity taught the class each year. According to the course description, students learned about ethnicity as a "central part of the lives of all Americans." Another course goal was for students to learn about their own backgrounds while studying the histories of other cultures. Students at this school had the choice to take ethnic studies as a distribution requirement among other electives; their other choices were constitutional law or economics. While Mariko was interested in taking ethnic studies, her adviser strongly discouraged her from registering:

I did want to take [ethnic studies]. But not because it would be an easy grade. It's just that I never really had the chance to learn about this stuff 
[multicultural] before. It sounded like an interesting class where I would actually learn new information. But my adviser said I needed to challenge myself more. She said l'd do myself a favor by taking economics instead.

Like Ryan, Mariko mentioned that many of her classmates who took ethnic studies thought that it was all "fun and games," meaning that the course did not appear to address more serious issues such as the histories of counter-cultures, oppositional narratives, and racism. According to the course syllabus, major assignments included creating cultural artifacts such as artwork, poems, and songs; developing a family tree based on one's ancestry; and researching topics such as ethnic holidays, recipes, and traditions. The class also took fieldtrips to the local German American Cultural House and the Polish American Community Center. In all, Mariko's teacher structured the class around the notion that cultural identification has been equally available to all Americans without considering how people of color have not always had the option to celebrate their identities for recreational purposes. As Waters (2006) pointed out:

The symbolic ethnic tends to think that all groups are equal; everyone has a background that is their right to celebrate and pass onto their children... When White Americans equate their own ethnicities with the socially enforced identities of non-White Americans, they obscure the fact that the experiences of Whites and non-Whites have been qualitatively different and the United States and that the current identities of individuals partly reflect that unequal history. (pp. 201-202)

By tailoring the course activities to primarily represent European ethnic groups, the teacher ignored the histories and the very presence of the area's populations of color, including Asian Americans. For instance, several local organizations, created by or for communities of color, were located within 10 miles of Mariko's school, and the class could have visited them in addition to the European American cultural centers. It is possible that the teacher did not intend to be exclusionary but may have lacked the requisite knowledge to more inclusively teach ethnic studies. Regardless of intent, however, the failure to include varied group experiences in the course sent an unspoken message that Americans of color are second-class citizens who do not deserve equal attention in the curriculum.

Another core subject where participants occasionally learned about Asian American experiences was in social studies. Shinichi, for instance, mentioned that one of his social studies teachers never brought up what happened to Japanese Americans during World War II. However, there was a one-paragraph description of the topic in the assigned course textbook that was never addressed in class. Shinichi reflected:

You could say I was just in shock. Speechless. I mean, I never heard of this stuff before. I asked my parents what they knew, but they said they had no clue. So I looked up some of this stuff. But I doubt anyone [his peers] really paid attention to [all of] this. So there was, like, I think, a paragraph on the camps. Basically, stated that the Japanese went 
peacefully into these "special camps" that the government made for them. They [the textbook authors] didn't bother saying how many people went and the bad stuff that happened, like how families lost everything. They made it sound like the camps really "helped" Japanese people. This didn't match what I found out was for real. That all of these people were put through such hell. But my teacher never, ever, even once, ever mentioned anything.

Shinichi speculated that he, as the lone Asian American in class, was probably the only one who noticed that the textbook even mentioned the incarceration. By not even mentioning this topic at all, Shinichi's teacher sent an unspoken message that what happened to Japanese Americans during World War II was not a significant part of American history. Like Mariko's teacher, it is also possible that Shinichi's teacher never learned about Japanese American history because he did not receive the proper academic training to teach this information in a comprehensive manner to his own students.

While the participants generally reported that Asian Americans were excluded from the curricula, a few White teachers did incorporate Asian Americans into discussions but never on a regular basis. For instance, Haruka recalled a lecture that one of her favorite history teachers gave:

[My teacher] is Irish [American]. He said that his great-grandparents went through really bad discrimination. He also said Blacks and Chinese and other groups were not treated equal[ly]. He told us about how the Irish were treated horribly; you know, like the signs that read, "No Irish need apply." And how Blacks were denied the right to vote and weren't even considered people. We even learned about the Chinese in my American history class, about the Gold Rush and railroads.

Despite his more inclusive approach that included incorporating the history of early Chinese Americans, Haruka's teacher did not discuss the experiences of other Asian American groups. He did inform students at the beginning of the year that time constraints would restrict the scope of groups and topics covered. Similarly, Mariko also mentioned that one of her high school social studies teacher, a White woman who is a native of California, spent an entire day going over the World War II incarceration in fairly descriptive detail, even going so far to mention that the U.S. made a "horrible mistake" in sending Japanese Americans to the camps. However, Haruka was the only participant who learned about the incarceration in such a detailed manner.

Moreover, the participants learned virtually nothing about the institutional racism that Asian Americans have endured in the past or present. White teachers who discussed contemporary racism often defined such issues in strictly BlackWhite terms. Danny mentioned the following example:

In social studies, yeah, we did talk about race. But Mr. Toby never mentioned Asians. Everything was about Black people. One time I complained to my [White] friend and he brought it up in class. I felt like a fool; I didn't want him [his friend] to bring attention to it. But [teacher] just 
laughed in my direction, and said "Asians? Racism? He said that we [Asian Americans] haven't been involved in the struggle. I remember feeling worthless. Do we not matter to anyone?

Based on Danny's account, his teacher did not appear to be familiar with Asian American history. In fact, from this account, it appeared that students were taught misinformation that Asian Americans were not involved in interracial social movements. Naomi had a similar experience of not learning about Asian Americans within the context of the Civil Rights Movement:

In school, we've learned about Black people too, you know, Martin Luther King, Malcolm X, Rosa Parks, you know, the usual. We talked about Cesar Chavez a little too, but not too much. You know, we didn't talk about any Asian [American] people, what happened to them in history, who our leaders were. Although I can't, like, think of any [Asian American leaders] off the top of my head.

As Naomi mentioned, reciting significant African American figures was more of an automatic mental process, whereas she struggled to recall the specific names of notable Asian Americans. Naomi's experience mirrors what Pang (2006) highlights as a common problem—namely the absence of Asian American experiences in multicultural education:

Because little information about AAs [Asian Americans] is found in US social studies and history books, the exclusion of information denies their existence and conveys the idea that their experiences were not important to society in general. (p. 74)

In summary, each participant reported experiencing little discussion of multiculturalism in her or his school's curriculum, which appeared to be attributed to a general lack of academic training and knowledge by their White teachers. If diversity issues were covered in class, a heavy emphasis was placed on BlackWhite racial issues or privileged the experiences of White ethnic groups over other groups of color (Waters, 2006). Finally, in the few instances that the participants actually learned about Asian American experiences at school, they reported acquiring information from their teachers or textbooks that were not comprehensive, detailed, or explained in larger historical, political, or social contexts.

\section{Images of Cultural Pathology and Other Orientalist Stereotypes}

The participants reported that, when Asian/American themes were covered in class, they tended to focus on global and international issues rather than multicultural content specifically focusing on Asian American cultures, experiences, and histories in the U.S. context. Specifically, when teaching about Asian/American experiences in its entirety, their White teachers generally taught 
isolated units on Asian art, geography, history, literature, music, politics, religion, and sports. As will be discussed, the way that the content was taught often reinforced Orientalist stereotypes of the cultural exoticism-pathology binary, which depicted Asian/Americans as either exotic foreigners or the culturally problematic/strange (with nothing in between), or reproduced stereotypes of racial sameness.

Haruka shared an example of how her White female teacher included a writing unit that contained inaccurate information:

Freshman year, my teacher was pretty new and trying to be [multi] cultural. She told us that it's important that we learn about other cultures. So she taught us about haiku. She started by saying that haiku is poetry of China and Japan! It's like, uh, no, it's actually Japanese. Anyway, she had us write our own poems. She used the example that Rosie O'Donnell uses haiku in her blogs to get us started.

As Haruka pointed out, her teacher made some serious errors. Foremost, haiku is specifically a Japanese form of poetry. That is, it is not culturally Chinese or even pan-Asian. Also, while Rosie O'Donnell is known to have blogged about her life on her personal website, the form she uses does not follow the structure of haiku. Rather, O'Donnell's style could more appropriately be described as free form, whereas haiku is regulated by specific structural rules. Furthermore, the teacher conflated Chinese and Japanese cultures, a mistake that is based on the racialized notion that "all Asians are the same" without consideration of the historical animosities and inter-group diversities between Chinese/Americans and Japanese/Americans (Wu, 2002). As Haruka pointed out: "I would say that most [White] people at my school really can't tell the difference, [between] Chinese, Japanese, you know. So, this [lesson] was pretty worthless." She also made the point that "teachers should really check their information before actually teaching it."

Other participants mentioned that discussions related to Asian history and politics usually were limited to themes that intersected with the Yellow Peril image. All participants noted that they learned about the Pearl Harbor incident but from a perspective that privileged the narrative of American exceptionalism. Danny and Shinichi also reported that their White teachers thoroughly critiqued the pre-1945 Japanese empire. Significantly, the critiques did not focus on the history of Japan's brutality against millions of people throughout East and Southeast Asia who had suffered horrific losses and trauma under Japanese colonial rule. Rather, their White teachers mostly discussed Japan's aggression toward the U.S.Mest, which privileged Eurocentric approaches to world history that certainly were not considerate of multiple perspectives.

When discussing current events in international contexts, topics generally related to news that received negative publicity from the American/Western media. For instance, Mariko's history teacher, a self-described specialist of comparative history and politics who is also White, frequently talked about government corruption in China, Myanmar (formerly Burma), and Thailand. As 
another example, after the 2008 Beijing Olympics and during a lesson on media monopolies in non-democratic nations, he brought up the much-publicized concern that the Chinese government was censoring and even incarcerating protestors. In all, Mariko and other participants felt uncomfortable when their White teachers taught about Asia from a cultural-pathology standpoint. As Ryan aptly mentioned, "Well, you could say that I, you know, felt singled out when these things were mentioned [in class]. And even if nobody said anything, it still felt that all eyes were on the Asian kids when these things came up."

Significantly, a review of each school's course offerings showed that Naomi's high school, which is one of the area's more affluent suburban public high schools, was the only one that actually included Asian American texts as required readings. Asian American content was included in an Advanced Placement (AP) American Literature. The Joy Luck Club by Amy Tan singularly represented what was labeled as "Asian Literature," even though Tan is a USborn Chinese American. The teacher, a White woman, created handouts with weekly reader-response questions on topics that asked students to write about how the Chinese American daughters coped with so-called oppressive Asian/Chinese cultural values such as the degradation of girls and women. Many of the questions perpetuated Orientalist representations of Asian American culture, particularly the misguided stereotypes that Asian Americans are foreigners, most Asian American men are misogynistic, and Asian immigrants are unwilling to assimilate.

Interestingly, Mariko recalled that one of her high school English teachers included a book by a Japanese American author:

One time, my English teacher did include a Japanese [American] author. Well, she [English teacher] had an optional reading list on some [World War II Japanese American] camp novels like Farewell to Manzanar [by Jeanne Wakatsuki Houston]. Most of the American [White] kids who read it really didn't care for it.

Only 3 out of the 35 total books recommended or required (15 were required) were by Black authors: Chinua Achebe, Maya Angelou, and Toni Morrison. Morrison's The Bluest Eye was the only required work written by an American of color. In comparison, Jeanne Wakatsuki Houston was the only Asian American writer listed, but Farewell to Manzanar was an optional reading. In one of Naomi's high school English classes, her White teacher assigned Yoshiko Uchida's Picture Bride. Naomi noted that while she enjoyed reading the book, she felt that some of her White classmates could not distinguish between fact and fiction, which she largely attributed to ignorance. For instance, the protagonist of Picture Bride was a young Japanese woman who arrived to San Francisco to fulfill an arranged-marriage obligation under the assumption that she would meet a Japanese man in her age range. However, she ended up marrying a much older Japanese immigrant who fabricated his age out of desperation to marry quickly. Naomi recalled a time when a White classmate asked why the Japanese practice arranged marriages, and this student also made the comment 
that people do not "value" women's rights. Fortunately, the teacher stepped in and explained that most Japanese people no longer participate in arranged marriages. Even though it was not explicitly directed toward her personally, Naomi still felt that the comment negatively stereotyped Japanese culture. As the only Asian American student in class, she felt that unnecessary attention was drawn to an issue that did not even mirror her experiences.

\section{Implications for Practice}

From a broader comparative perspective, the findings from this case study mirror what Ladson-Billings (2003) described as a discourse of invisibility and a process of erasure where "an incoherent, disjointed picture of those who are not White" (p. 4) pervades how Americans of color are represented in the curricula. As scholars have noted, the causes of the problem are complex but could be attributed to the following realities: the mainstream U.S. K-12 teachers tend to have limited experiences with diversity and teach based on their own cultural frameworks; U.S. teacher-preparation programs tend to privilege and reproduce Eurocentric mainstream norms, values, and worldviews; and consequently and related to all of the above dynamics, Eurocentrism continues to permeate the cultures of K-12 schools (Banks, 2009; Cross, 2004).

As suggested from the participants' narratives, multiculturalism was conceptualized in narrow Black-White terms or around superficial aspects of cultural diversity. Consequently, the way that they learned multicultural content did not have much of an educational value. That is, the participants themselves did not have consistent opportunities to learn accurate information about their ancestry and community's experiences through the curricula, while non-Asian American students acquired "knowledge" that was distorted, inaccurate, and incomplete. By primarily learning about Asian arts, crafts, food, and music, or about Japan in an international-only context, students did not learn about the complexities of Asian/American or Japanese/American identities in ways that represented multiple generations, histories, and perspectives. Similarly, none of the participants recalled learning about other Asian American ethnic groups beyond East Asian Americans such as Chinese Americans and Japanese Americans, which shows significant gaps that teachers need to address in order to more accurately represent the diversity within the pan-ethnic Asian American community that would include, for instance, South Asian Americans and Southeast Asian Americans (Ngo, 2006).

The findings also parallel the results from other studies that analyzed the educational experiences of other Asian American ethnic groups. After interviewing both Hmong American students and mostly White teachers, Lee (2005) found that "despite the rhetoric regarding the importance of diversity, multicultural education was not central to the school's curriculum" (p. 24). Other research on the schooling experiences of specific ethnic groups including East 
Asian Americans (e.g., Chae, 2004; Lee, 1996; Lew, 2006) and Southeast Asian Americans (e.g., Conchas \& Pérez, 2003; Lee, 2005; Ngo, 2010) also suggests that U.S. K-12 schools continue to teach about Asian/Americans in ways that reinforce the cultural exoticism-pathology binary and images of Asian racial sameness. Comparing the findings of this case study to other research suggests that Asian American students, regardless of their backgrounds, are the invisible victims of having significant mis/information about their backgrounds taught in academic environments. Thus, these findings concur with Kaomea (2000), who writes that "well-intended multicultural movements" and "increased visibility" ( $p$. 341) of underrepresented groups in the curricula may not be sufficient to remedy the mirrors-window gap, as including "multicultural" content that reinforces racial stereotypes does more harm than good.

To start incorporating Asian/American experiences into the curricula in ways that would promote accurate and respectful inclusivity, teachers could begin scaffolding learning experiences by first teaching basic information such as highlighting the contributions of individual Asian Americans. After students have acquired this basic knowledge, teachers could then intentionally structure comparative units that analyze Asian American experiences in relation to other populations of color (Coloma, 2006), which could approach a Level 3/Transformative Approach (Banks, 2006). For instance, for teachers of language arts, critical questions about authorship and identity politics could be integrated into classroom discussions (Harris, 2007). In the case of Naomi's teacher, The Joy Luck Club could have been taught more critically. Despite the book's popularity in mainstream (White) audiences, it has not been universally embraced by the Asian American scholarly community. Chin (1991) and other Asian American male scholars have been outspoken critics of popular Asian American women writers such as Maxine Hong Kingston and Amy Tan for representing Asian American men according to what they see as racist stereotypes. While the intent is not to encourage the removal of books like The Joy Luck Club from any reading lists, Naomi's teacher could have benefited from researching the debates pertaining to issues of Asian American literary representations to help students understand the multiple debates and viewpoints surrounding these contentious issues (Endo, 2009).

Finally, while Asian Americans across ethnic groups share several common experiences, primarily in terms of being lumped together and racialized (Espiritu, 1993), Lee (2005) reminds us that "the diversity of the Asian American category makes it impossible to talk about a single Asian American culture, identity, or experience" (p. 17). The above analysis also applies to how teachers should teach about specific ethnic groups such as Japanese Americans. For example, while the mainstream narrative of the Japanese American experience during the World War II era is critical to discuss in the classroom because the incident represents one of the most troublesome instances of governmentsanctioned mass incarceration, racial profiling, and segregation in U.S. history, there is also a need to present information that showcases the diversity within the Japanese American community including their contemporary experiences. The 
participants in this study, as the children of new-wave Japanese immigrants, offer unique insights about identity, multiculturalism, and race, and their perspectives should be incorporated to help their peers and teachers alike gain more balanced and diverse perspectives about being Asian/American and Japanese/American. Ultimately, through consistent exposure to diverse within-group experiences in the classroom setting and curricula, harmful and reductive stereotypes about any population will be identified and removed to make room for more balanced and inclusive content that will ideally promote relevant and respectful learning experiences for all students.

\section{References}

Adler, S. M. (1998). Mothering, education, and ethnicity: The transformation of Japanese American culture. New York: Garland.

Amos, Y. T. (2008). Stereotypes in disguise: The dual school lives of Japanese immigrant students. International Journal of Multicultural Education, 10(1), 1-16.

Apple, M. W. (1990). Ideology and curriculum (2nd ed.). New York: Routledge.

Banks, J. A. (2006). Cultural diversity and education: Foundations, education, and curriculum (5th ed.). Boston: Allyn and Bacon.

Banks, J. A. (2009). Teaching strategies for ethnic studies (8th ed.). Boston: Allyn and Bacon.

Chae, H. S. (2004). Talking back to the Asian model minority discourse: Koreanorigin youth experiences in high school. Journal of Intercultural Studies, 25, 59-73.

Chin, F. (1991). Come all ye Asian American writers of the real and fake. In. J. P. Chan, F. Chin, L. F. Inada, \& S. Wong, The big AllIEEEEE! An anthology of Chinese American and Japanese American literature (pp. 1-91). New York: Meridian.

Clandinin, D. J., \& Connelly, F. M. (2000). Narrative inquiry: Experience and story in qualitative research. San Francisco: Jossey-Bass.

Coloma, R. S. (2006). Disorienting race and education: Changing paradigms of the schooling of Asian American and Pacific Islanders. Race Ethnicity and Education, 9, 1-15.

Conchas, G. Q., \& Pérez, C. C. (2003). Surfing the "model minority" wave of success: How the school context shapes distinct experiences among Vietnamese youth. New Directions for Youth Development, 100, 41-57.

Cross, B. (2005). New racism, reformed teacher education, and the same ole' oppression. Education Studies, 38, 263-274. 
Endo, R. (2007). Japanese immigrant communities in contemporary contexts: Rethinking education and literacy. Paper presented at the Association for Asian American Studies Annual Meeting. New York, NY.

Endo, R. (2009). Complicating culture and difference: Situating Asian American youth identities in Lisa Yee's Millicent Min, girl genius and Stanford Wong flunks big-time. Children's Literature in Education: An International Quarterly, 40(3), 235-249.

Espiritu, Y. L. (1993). Asian American panethnicity: Bridging institutions and identities. Philadelphia: Temple University Press.

Glenn, E. N. (1988). Issei, Nisei, war bride: Three generations of Japanese American women in domestic service. Philadelphia: Temple University Press.

Goodwin, A. L. (2011). Curriculum as colonizer: (Asian) American education in the current U.S. context. Teachers College Record, 112, 3102-3138.

Grant, C. A., \& Sleeter, C. E. (2006). Turning on learning: Five approaches to race, class, and gender (5th ed.). New York: John Wiley \& Sons.

Harris, V. J. (2007). Master narratives and oppositional texts: Aesthetics and Black literature for youth. In D. Reiser, L. Bresler, \& T. Constantino (Eds.), The handbook of research in the arts, part two (pp. 10071020). Dordrecht, The Netherlands: Springer.

Houston, J. W., \& Houston, J. D. (1973). Farewell to Manzanar. San Francisco: Bantam.

Josselson, R. (2006). Narratives in action. Narrative Inquiry, 16(1), 3-10.

Kaomea, J. (2000). A curriculum of aloha? Colonialism and tourism in Hawai'i's elementary textbooks. Curriculum Inquiry, 30, 319-344.

Kibria, N. (2002). Becoming Asian American: Second-generation Chinese and Korean American identities. Baltimore: Johns Hopkins University.

Kondo, K. (1998b). Social-psychological factors affecting language maintenance: Interviews with Shin Nisei university students in Hawaii. Linguistics and Education, 9, 369-408.

Ladson-Billings, G. (2003). Lies my teacher still tells: Developing a critical race perspective toward the social studies. In G. Ladson-Billings (Ed.), Critical race theory perspectives on social studies: The profession, policies, and curriculum (pp. 1-11). Greenwich, CT: Information Age.

Lee, S. J. (1996). Unraveling the "model minority" stereotype: Listening to Asian American youth. New York: Teachers College Press.

Lee, S. J. (2005). Up against Whiteness: Race, school, and immigrant youth. New York: Teachers College Press.

Lew, J. (2006). Asian Americans in class: Charting the achievement gap among Korean American youth. New York: Teachers College Press. 
Lutz, C. A., \& Collins, J. L. (1993). Reading National Geographic. Chicago: University of Chicago Press.

Marinari, M. (2005). Racial formation and success among Korean American high school students. The Urban Review, 37, 375-398.

Morimoto, T. (1997). Japanese Americans and cultural continuity: Maintaining language and heritage. New York: Garland Press.

Morrison, T. (2000). The bluest eye. New York: Penguin Books.

Ng, J. C., Lee, S. S., \& Pak, Y. K. (2007). Contesting the model minority and perpetual foreigner stereotypes: A critical review of literature on Asian Americans in education. Review of Research in Education, 31, 95-130.

Ngo, B. (2006). Learning from the margins: Southeast and South Asian American education in context. Race Ethnicity and Education, 9, 51-65.

Ngo, B. (2010). Unresolved identities: Discourse, ambivalence and urban immigrant students. New York: State University of New York Press.

Osajima, K. (1988). Asian Americans as the model minority: An analysis of the popular press image in the 1960 s and 1980s. In G. Y. Okihiro, S. Hune, A. A. Hansen, \& J. M. Liu (Eds.), Reflections on shattered windows: Promises and prospects for Asian American studies (pp. 165-174). Pullman, WA: Washington State University Press.

Palumbo-Lin, D. (1999). Asian/American: Historical crossings of a racial frontier. Stanford, CA: Stanford University Press.

Pak, Y. K. (2002). Wherever I go, I will always be a loyal American: Seattle's Japanese American schoolchildren during World War II. New York: Routledge.

Pang, V. O. (2006). Fighting the marginalization of Asian American students with caring schools: Focusing on curricular change. Race Ethnicity and Education, 9, 67-83.

Said, E. W. (1978). Orientalism. New York: Vantage Books.

Style, E. (1996). Curriculum as window and mirror. Social Science Record, 33, 35-45.

Tan, A. (1989). The joy luck club. New York: G.P. Putnam's Sons.

Tuan, M. (1998). Forever foreigners or honorary Whites? The Asian ethnic experience today. New Brunswick, NJ: Rutgers University Press.

Uchida, Y. (1997). Picture bride: A novel. Seattle, WA: University of Washington Press.

Waters, M. C. (2006). Optional ethnicities for Whites only? In M. L. Andersen \& P. H. Collins (Eds.), Race, class, and gender: An anthology (pp. 198-207). Belmont, CA: Wadsworth. 
Wing, J. Y. (2007). Beyond Black and White: The model minority myth and the invisibility of Asian American students. The Urban Review, 39(4), 455-487.

Wu, F. H. (2002). Yellow: Race in American beyond Black and White. New York: Basic.

Yamaguchi, M. (2005). Discursive representation and enactment of national identities: The case of generation 1.5 Japanese. Discourse and Society, 16, 269-299. 